\title{
Improving IS Student Enrollments: Understanding the Effects of IT Sophistication in Introductory IS Courses
}

\author{
Asli Yagmur Akbulut \\ Grand Valley State University \\ Grand Rapids, MI, USA
}

\author{
Clayton Arlen Looney \\ University of Montana \\ Missoula, MT, USA
}

\author{
akbuluta@gvsu.edu
}

\section{clay.looney@business.umt.edu}

\section{Executive Summary}

The Information Systems (IS) discipline is facing a sharp downturn in student enrollments. Despite the steady decline in students pursuing the IS major, the demand for information technology (IT) professionals continues to increase. These trends indicate that there might be a shortage of qualified IT employees in the near future. In order to overcome this dilemma, academicians have recently begun to look for mechanisms targeted at improving IS enrollments. This study investigates how such a mechanism - IT sophistication - influences students' aspirations to pursue an IS degree. More specifically, the study suggests that IT sophistication, self-efficacy, outcome expectations, and interests are expected to independently and cumulatively affect students' choice of IS as their major. The data utilized to investigate this issue was collected from students enrolled in introductory IS courses at two large public universities. A total of 151 usable responses were obtained. The results indicate that the degree to which students perceive the IT to be sophisticated affects their aspiration to major in IS. Specifically, utilizing state-of-the art technologies that reflect current industry practices not only enhances students' confidence in their ability to successfully perform as an IS major, but also elevates students' expectations that valued rewards will be received by majoring in IS. In turn, strong self-efficacy and outcome expectations foster student interest in the IS discipline. Moreover, it was found that IT sophistication does not directly affect student interest. Rather, the effects of IT sophistication on interests are channeled indirectly through self-efficacy and outcome expectations. Similarly, our results did not provide support for the direct effects of self-efficacy and outcome expectations on choice goals. In contrast, choice goals develop through strong interests, and finally, interest serves as the primary mechanism through which goals to choose the IS major emerge.

Our findings suggest that deploying sophisticated IT in introductory IS classes can be used as a powerful lever to attract additional students the IS discipline. We encourage those who teach introductory IS courses to focus on state-

Material published as part of this publication, either on-line or in print, is copyrighted by the Informing Science Institute. Permission to make digital or paper copy of part or all of these works for personal or classroom use is granted without fee provided that the copies are not made or distributed for profit or commercial advantage AND that copies 1) bear this notice in full and 2) give the full citation on the first page. It is permissible to abstract these works so long as credit is given. To copy in all other cases or to republish or to post on a server or to redistribute to lists requires specific permission and payment of a fee. Contact Publisher@,InformingScience.org to request redistribution permission. of-the-art technologies that reflect current industry practices. Utilizing these technologies also has the potential to increase student success in the classroom, provide a richer and more engaging learning environment for students, and help students become more attractive to recruiters.

Despite the knowledge gained herein, the study has certain limitations. The 
constructs in the research model represent a subset of the factors that could affect student choices. In order to develop a more comprehensive set of intervention strategies targeted at student recruitment, a wider range of factors should be considered. Also, future studies should utilize additional methods using complementary samples to identify the boundary conditions of our findings.

Keywords: Information systems education, curriculum, enrollment, recruitment, social cognitive career theory, information technology sophistication.

\section{Introduction}

A paradoxical situation confronts the Information Systems (IS) discipline. On one hand, the number of IS majors has declined in United States (George, Valacich, \& Valor, 2005). On the other hand, the demand for information technology (IT) professionals continues to accelerate (Hecker, 2004). If these trends persist, there will be a severe shortage of qualified IT employees in the near future. In order to overcome this dilemma, it is vital for educators to develop and implement programs that attracts larger pools of students to the IS field.

Even though the IT community has been aware of the enrollment decline and its potential consequences, very little academic research has been conducted in this area (Lomerson \& Pollicia, 2006). Despite the lack of empirical data, George et al. (2005) emphasize the important role that introductory IS courses can play in enhancing student recruitment efforts. According to this line of logic, introductory courses provide a unique opportunity to attract students to the IS major, as most students enrolled in these courses have yet to finalize their decisions about which major to pursue. In particular, when the pedagogical process fosters a productive learning environment, students might be more likely to develop aspirations to choose IS as their primary field of study. Therefore, it is imperative for IS programs to carefully choose the content, instructors, and IT, as deploying ineffective tactics can reduce educational value and stifle student recruitment. In terms of IT, George et al. (2005) suggested that the IT taught in introductory level courses should reflect current industry practices and utilize contemporary applications. In other words, the IT should be sophisticated. In introductory IS courses, the use of sophisticated IT, such as Enterprise Resource Planning (ERP) systems and computer-based learning (CBL) (e.g., TAIT), continues to grow rapidly (Kegely, 2006; Nam \& Smith-Jackson, 2007). However, the sophistication of these technologies varies considerably across institutions and academic settings. Although reports indicate that more sophisticated technologies produce desirable organizational outcomes (Chwelos, Benbasat, \& Dexter, 2001), their effect on student learning and recruitment remains an open empirical issue. Therefore, this study addresses the research question of whether the level of IT sophistication in introductory IS courses influences student uptake.

The remainder of this paper is organized as follows. The next section provides a brief overview of the underlying theory base. A research model and an interrelated set of hypotheses are then put forth. The research methodology is subsequently outlined and the results presented. The paper concludes with a discussion of the findings, as well as implications for theory and practice.

\section{Background and Theoretical Development}

This study utilizes Social Cognitive Theory (SCT) (Bandura, 1986; 1997) and Social Cognitive Career Theory (SCCT) (Lent, Brown, \& Hackett, 1994) to investigate the role of IT sophistication on students choice of IS as their major. SCT, as illustrated in Figure 1, is a robust and empirically validated model of individual behavior that has been extensively utilized in the IS field. SCT views psychosocial phenomena as mutually and reciprocally determined by environmental, personal, and behavioral factors (Bandura, 1986). 


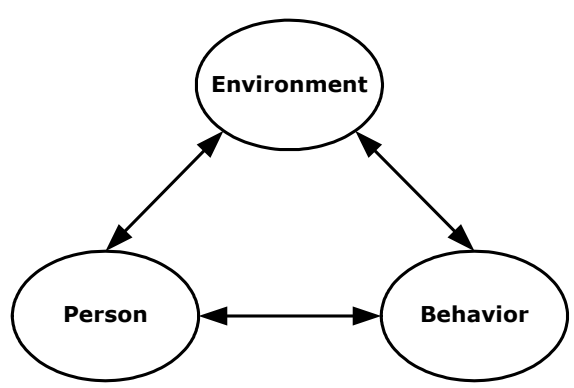

Figure 1: Social Cognitive Theory (Bandura, 1986)

Derived from SCT, SCCT represents a specific instantiation that focuses on the interplay among environmental, personal, behavioral factors to understand the development of academic and vocational interests, selection and pursuit of career-relevant choices, and performance and persistence in academic and vocational endeavors (Lent, Brown, \& Hackett, 1994).

Environmental Factor. Environmental factors encompass the temporal and spatial forces beyond an individual's boundaries (Bandura, 1986). These factors can influence and be influenced by behavioral and personal factors. According to SCCT, individuals do not make educational and career choices in a vacuum, as they are cognizant of particular environmental circumstances. Therefore, environmental factors are expected to pervade every stage of the academic and career development process (Lent et al., 1994).

The literature has identified several environmental factors that individuals perceive as aiding their efforts to implement a particular educational or occupational goal. For instance, a variety of support factors have been mentioned in the literature, including encouragement from others, role models, instrumental assistance, and financial resources (Lent et al., 2002). Beyond these mechanisms, the utilization of IT as a pedagogical tool has fundamentally altered the educational environment. According to SCT, environmental forces, which include the technological tools and resources at one's disposal, influence people and behavior in a fashion similar to the factors suggested in the literature (Looney, Valacich, Todd, \& Morris, 2006). Logically, when people are equipped with superior resources, such as more sophisticated technologies, the likelihood of accomplishing specific behaviors improves. In the context of our study, IT sophistication refers to the degree to which the IT taught in an introductory IS course reflects the technologies that contemporary organizations utilize. In terms of career preparation, student use of sophisticated technologies will equip them with the skills needed to succeed in the workplace. Therefore, we expect IT sophistication to play an influential role in student psychology and behavior.

Personal Factors. Individuals posses certain traits, histories, and cognitive resources to deploy during their interactions with the environment. Central to SCCT are the concepts of self-efficacy, outcome expectations, and interests (Lent et al., 1994).

Self-efficacy can be defined as a perception of one's ability to organize and execute courses of action to accomplish a particular task (Bandura, 1986). Self-efficacy functions by providing individuals with a set of beliefs regarding their capabilities to exercise control over their actions and the environment. Self-efficacy plays a central role in computing, including training (Agarwal, Sambamurthy, \& Stair, 2000; Johnson \& Marakas, 2000), technology acceptance (Taylor \& Todd, 1995), technology use (Compeau \& Higgins, 1995a; 1995b), and virtual organizations (Staples, Hulland, \& Higgins, 1999) to name a few. Since self-efficacy judgments are situational and task-specific (Marakas, Yi, \& Johnson, 1998), our study focuses on a context-specific form of self-efficacy, which we define as an individual judgment of one's capability to perform effectively as an IS major. 
Outcome expectations capture the perceived likelihood that favorable consequences will occur as a result of a particular action (Bandura, 1986; 1997). Although rewards ultimately materialize after one has acted, individuals do consider the prospective likelihood that their actions will produce favorable results before engaging in the activity. Individuals are more likely to undertake behaviors that they expect to result in favorable outcomes. Unless one expects the behavior to produce favorable outcomes, the individual may lack the necessary motivation to undertake the behavior (Bandura, 1986; 1997). Outcome expectations can be categorized into three major forms - social (e.g. recognition), self-evaluative (e.g., sense of accomplishment), and physical (e.g., angst) (see Bandura, 1986). Like self-efficacy judgments, outcome expectations target the outcomes that transpire as a result of performing specific behaviors. Therefore, we define outcome expectations as the perceived likelihood that valued rewards will be received as a result of pursuing an IS major.

Interest can defined as an emotion that arouses attention to, curiosity about, and concern with a particular educational path (Lent et al., 1994). In this study, the target of interest specifically focuses on majoring in IS. Even though individuals may try out and pursue many different activities throughout their formative years, they ultimately develop distinctive patterns of academic and career interests, as certain activities differentially intrigue people to varying degrees over time (Bandura, 1986; Lent et al., 1994).

Behavioral Factor. In the context of career-related choices, the behavior in question is operationalized as choice goals, which can be defined as the determination to engage in a particular educational or occupational activity (Bandura, 1986). Specific to this study, choice goals refers to a students' aspirations to choice IS as a major. According to the SCCT, choice goals play an important role in the self-regulation of behavior. People set goals to organize and guide their behavior, as well as to increase the likelihood that desired outcomes will be attained. Goals play an important role in decision making theories, including career choice decisions. In this respect, career plans, aspirations, and expressed choices are considered as goal mechanisms (Lent et al., 1994).

\section{Research Model and Hypotheses}

Figure 2 represents the research model utilized in our study. The research model consists of one environmental factor (IT Sophistication), three personal factors (self-efficacy, outcome expectations, and interest), and one behavioral factor (choice goals). As illustrated, IT sophistication, self-efficacy, outcome expectations, and interests are expected to independently and cumulatively affect choice goals. The following sections describe the hypotheses in detail.

In an introductory IS course, technologies constitute a resource that is embedded within a student's learning environment. As such, IT Sophistication is included in our model as an environmental factor. Studies indicate that environmental factors play an important role in shaping individuals' experiences that lead to the development of particular educational and career interests and choices (Lent et al., 1994). In his discussions about the interplay among personal and environmental factors on behavior, Bandura $(1999,2000)$ stated that most external influences affect human functioning through intermediary self processes rather than directly. Along these lines, Lent, Brown, Nota, and Soresi (2003) provided evidence that environmental factors indirectly affect choice behavior through self-efficacy, outcome expectations, and interests. Consequently, rather than affecting choice goals directly, the model proposes that IT sophistication will influence student choice behaviors through the personal factors specified in the model. 


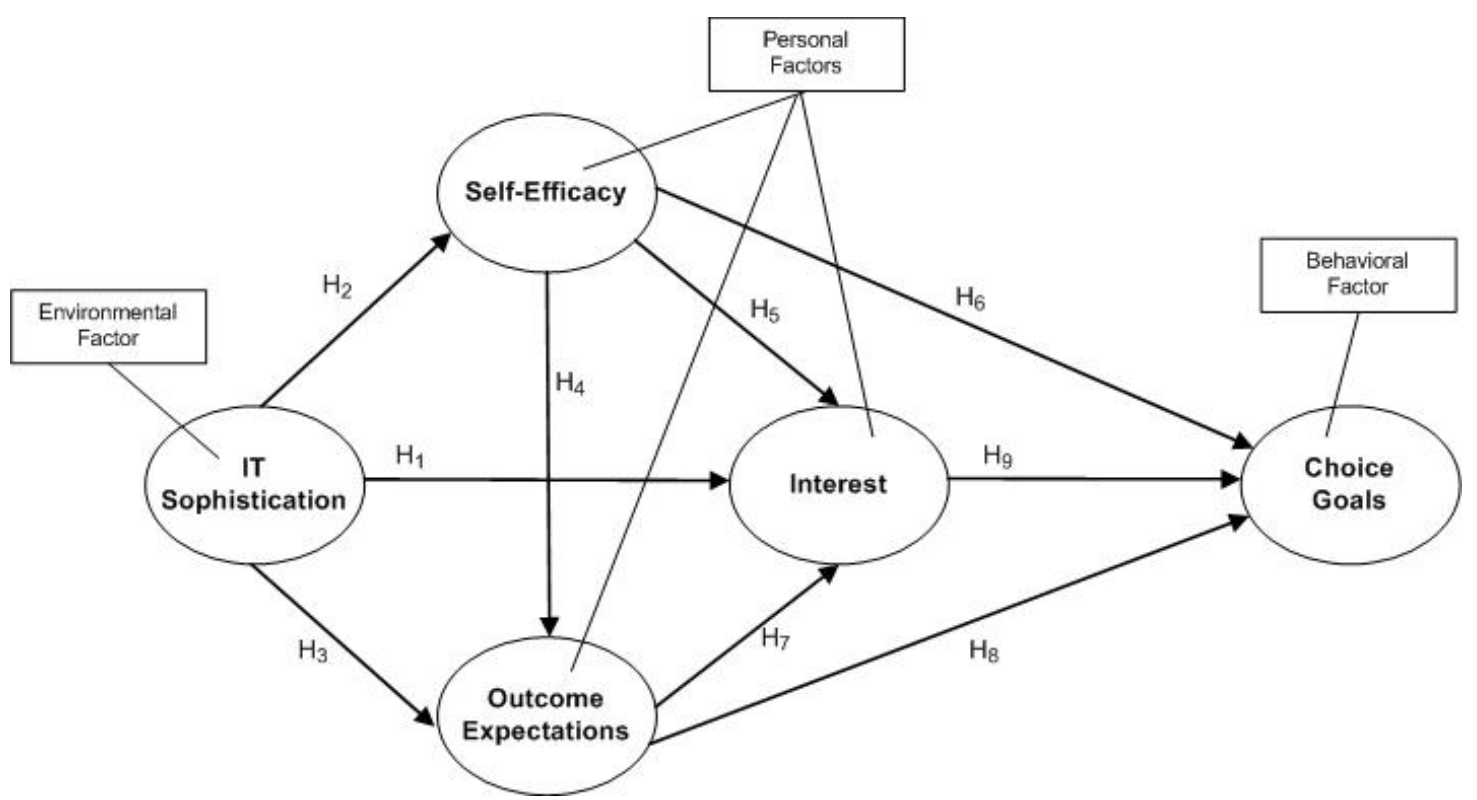

Figure 2: Research Model

Specific to interests, research suggests that students prefer to engage in learning activities that relate directly to contemporary industry practices (Kamoun \& Selim, 2007). In this respect, being exposed to modern, state-of-the-art information technologies (i.e., sophisticated) that are similar to those utilized in organizations can trigger students' interest in the IS field. Compared to technologies to which student have been already exposed (e.g., web browsers, electronic mail), sophisticated technologies are more novel. Novelty represents a primary mechanism that piques interest (Berlyne, 1978). When individuals interact with a new object, the associated novelty makes the object seem more compelling. Moreover, as students gain hands-on experience with these applications, they develop a better understanding of the IS field and the types of technologies that IS professionals typically use. We, therefore, expect IT sophistication to influence interest.

\section{$H_{1}$ : IT sophistication will have a significant positive influence on interests.}

According to SCT, environmental factors, which include the technological tools and resources at one's disposal, can have a profound influence on self-efficacy and outcome expectations (Bandura, 1986, 1997). Since more sophisticated resources better equip individuals to perform certain behaviors, we expect that IT sophistication will affect students' self-efficacy perceptions. Students who are trained using the more sophisticated technologies are more likely to develop higher levels of confidence in their abilities to perform as an IS major, as they believe that they are acquiring the technological skills needed to succeed in the field.

\section{$\mathrm{H}_{2}$ : IT sophistication will have a significant positive influence on self-efficacy.}

Similarly, IT sophistication may promote outcome expectations, as state-of-the-art technologies reflect current industry practices and may, therefore, provide clues about the consequences that may occur as a result of pursuing an IS major (Compeau \& Higgins, 1995a). When students perceive that they are being exposed to contemporary applications, they are apt to believe that they are more likely to obtain rewards as a result of majoring in the IS field.

\section{$H_{3}$ : IT sophistication will have a significant positive influence on outcome expectations.}

The relationship between self-efficacy and outcome expectations has been repeatedly studied in the IS literature. Research has shown that self-efficacy beliefs influence outcome expectations 
(Compeau and Higgins, 1995a; 1995b; Compeau, Higgins, \& Huff, 1999; Looney et al., 2006). People expect to achieve desirable outcomes in activities at which they deem themselves as capable. In essence, an individual who possesses a strong sense of efficacy is more likely to believe that favorable consequences will arise from her or his actions. Therefore, it is reasonable to assume that students who have higher levels of self-efficacy will develop robust outcome expectations.

\section{$H_{4}$ : Self-efficacy will have a significant positive influence on outcome expectations.}

Lent et al. (1994) has demonstrated that perceptions of self-efficacy play an important role in the formation of educational and vocational interests and behaviors. People tend to form enduring interests in activities in which they view themselves as capable (Bandura \& Schunk, 1981). Thus, it is reasonable to assume that students with higher levels of self-efficacy will be more interested in pursuing majors and careers within the field of IS.

\section{$H_{5}$ : Self-efficacy will have a significant positive influence on interest.}

Self-efficacy beliefs are also assumed to have direct effects on choice goals. Bandura (1986) has proposed that self-efficacy affects an individual's goals to perform a specific behavior. When high self-efficacy prevails, individuals are more likely to set goals to engage in a particular behavior. As such, students who are confident in their abilities to perform as an IS major would be more likely to develop aspirations to major in the IS field.

\section{$H_{6}:$ Self-efficacy will have a significant positive influence on choice goals.}

Similar to self-efficacy, an individual's expectations about the consequences of pursing educational and vocational paths shape interests (Lent et al., 1994). In essence, when a student expects pursuing a major or career in the IS field will result in favorable outcomes, he or she will be more likely to find that IS field compelling and develop an interest.

\section{$H_{7}$ : Outcome expectations will have a significant positive influence on interest.}

Outcome expectations can also affect choice goals directly. People develop goals, in part, based on the rewards they expect to receive. The higher the likelihood of obtaining valued outcomes, the more likely that people will adopt particular career goals.

\section{$H_{8}$ : Outcome expectations will have a significant positive influence on choice goals.}

In addition to self-efficacy and outcome expectations, we anticipate that interest will influence choice goals. Research indicates that people tend to select academic and career options that match their primary interests (Holland, 1985). Emergent interests lead to cognized choice goals for further activity exposure (i.e. intention plans, or aspirations to engage in a particular academic or career direction), fostering the development of goals to choose particular actions (e.g., declaring a corresponding major) (Lent et al., 1994). Therefore, students who are interested in the IS field will be more determined to major in the IS discipline.

\section{$H_{9}:$ Interest will have a significant positive influence on choice goals.}

\section{Method}

\section{Sample and Procedure}

Study participants consisted of students enrolled in an introductory level information system course at two large state universities. At each university, the level of IT sophistication varied considerably, as one university emphasized ERP systems, whereas office applications (e.g., word processing, spreadsheets) served as the primary technologies in the other. Surveying students who were exposed to different levels of IT sophistication served to increase sample variation. Restrict- 
ing the survey to a single institution could have biased the results, preventing us from making broader inferences.

A web-based survey was used to collect the data for the study. The survey was administered during the last week of classes at each university, as the course provided most students a preliminary introduction to the IS discipline. Students volunteered to participate in the survey and were provided course credit in return for their participation. The survey consisted of a consent form, a background questionnaire, and a set of instruments capturing the five factors in the research model. The software counterbalanced the instruments so that the measures were presented in a random order. Within each instrument, items were also randomized.

A total of 151 usable responses were obtained. Forty two percent of the respondents were female and respondents averaged 21.6 years of age $(S D=2.23)$.

\section{Construct Operationalization}

A total of five scales were required to test the research hypotheses. A review of literature was undertaken to identify existing scales. Whenever possible, previously validated scales were used. Adapted and developed measures were subjected to rigorous pre-testing in separate studies. Selfefficacy was measured with a six-item scale. The response format for the questions included an 11-place Likert type scale ranging from 0 (Cannot Do) to 10 (Certain Can Do). A ten-item scale was used to measure outcome expectations. The response format consisted of an 11-place Likerttype scale anchored by 0 (Will Never Occur) to 10 (Will Always Occur). Interest, choice goals, and IT sophistication were measured using five, four, and six items respectively. These scales were adapted from previous studies (Chwelos et al. 2001; Lent et al., 2002). For each scale, the response format consisted of 7-place Likert-type response formats ranging from 1 (Strongly Disagree) to 7 (Strongly Agree).

\section{Analysis}

Partial Least Squares (PLS) was used for data analysis (Barclay, Higgins, \& Thompson, 1995; Wold, 1985). More specifically, PLS-Graph Version 3 was utilized (Chin, 1998). PLS is classified as a latent structural equations modeling (SEM) technique that utilizes a component based approach to estimation (Joreskog \& Sorbom, 1993). PLS was chosen over regression analysis because, as a SEM technique, it allows all paths to be analyzed simultaneously. Also, PLS was chosen over LISREL because it is a more suitable technique when the objective of the study involves theory building (Barclay et al., 1995; Gefen, Straub, \& Boudreau, 2000). The present study represents one such case.

The psychometric properties of the measurement model were confirmed prior to estimating structural model parameters, as discussed in the following sections.

\section{Measurement Model Analysis}

As recommended by Barclay et al. (1995), reliability and validity of the indicators and constructs were examined in three stages. Reliability of each construct was examined to ensure that the items collectively measured their intended construct consistently (Gefen et al., 2000). Reliability was assessed by examining the reliability of individual items (Cronbach's $\alpha$ ) and the composite reliability of constructs (Barclay et al., 1995; Fornell \& Larker, 1981). As shown in Table 1, both Cronbach $\alpha$ 's and composite reliability scores were well above the recommended level $(0.70)$ for acceptable reliability (Barclay et al., 1995; Fornell \& Larker, 1981). As such, the reliability of the scales was confirmed. 
Table 1: Construct Reliability, Correlations, and Discriminant Validity

\begin{tabular}{|lllllllll|}
\hline & & \multicolumn{7}{c|}{ Construct $^{\mathrm{a}}$} \\
\cline { 5 - 9 } $\begin{array}{l}\text { Con- } \\
\text { struct }\end{array}$ & $\alpha$ & CR & AVE & $\begin{array}{l}\text { IT- } \\
\text { SOPH }\end{array}$ & SE & OEXP & INTRST & CGOAL \\
\hline ITSOPH & 0.916 & 0.936 & 0.708 & $\mathbf{0 . 8 4 1}$ & & & & \\
SE & 0.953 & 0.963 & 0.815 & 0.321 & $\mathbf{0 . 9 0 3}$ & & & \\
OEXP & 0.951 & 0.959 & 0.702 & 0.391 & 0.500 & $\mathbf{0 . 8 3 8}$ & & \\
INTRST & 0.937 & 0.952 & 0.800 & 0.202 & 0.455 & 0.515 & $\mathbf{0 . 8 9 4}$ & \\
CGOAL & 0.977 & 0.984 & 0.937 & 0.020 & 0.395 & 0.390 & 0.643 & $\mathbf{0 . 9 6 8}$ \\
\hline
\end{tabular}

Note: $\propto=$ Cronbach's alpha. CR = composite reliability. AVE = average variance extracted. ITSOPH = IT sophistication, SE = Self-efficacy. OE = Outcome expectations. INTRST = Interest, $\mathrm{CGOAL}=$ Choice goals.

Convergent validity was also assessed at the individual item and construct levels by examining the individual item loadings and the average variance extracted (AVE) respectively (Fornell \& Larker, 1981). Individual item loadings of 0.707 demonstrate that the indicator shares more variance with its construct than error variance (Gefen et al., 2000). As shown in Table 2, individual items exhibited adequate loadings. No unacceptable cross loadings emerged. An AVE of 0.50 or greater implies that the construct as a whole shares more variance with its indicators compared to error variance (Fornell \& Larker, 1981). As shown in Table 1, the AVE score for each construct is well above the recommended level. Therefore, convergent validity was confirmed.

Discriminant validity was assessed by comparing the AVE values associated with each construct to the correlations among constructs (Barclay et al., 1995; Staples et al., 1999). The discriminant validity analysis is provided in Table 1. Diagonal elements show the square root of the AVE, whereas the off-diagonal elements show the correlations among constructs. In order to claim discriminant validity, the diagonal elements should be larger than any other corresponding row or column entry (Staples et al., 1999). According to the results, each construct sufficiently differed from the other constructs. Therefore, the measures demonstrated discriminant validity.

Given the results of the reliability and validity analysis, it was concluded that the scales exhibited excellent psychometric properties. 
Table 2: Constructs, Items, and Loadings

\begin{tabular}{|lcll|}
\hline \hline Construct/ltem & Loading & Construct/ltem & Loading \\
\hline Self Efficacy & & Outcome Expectations & \\
SE1 & 0.9096 & OEXP1 & 0.7647 \\
SE2 & 0.8985 & OEXP2 & 0.7634 \\
SE3 & 0.9124 & OEXP3 & 0.8741 \\
SE4 & 0.9078 & OEXP4 & 0.8589 \\
SE5 & 0.8543 & OEXP5 & 0.8333 \\
SE6 & 0.9313 & OEXP6 & 0.7967 \\
& & OEXP7 & 0.8484 \\
IT Sophistication & & OEXP8 & 0.8823 \\
ITSOPH1 & & OEXP9 & 0.8592 \\
ITSOPH2 & & OEXP10 & 0.8856 \\
ITSOPH3 & 0.8722 & & \\
ITSOPH4 & 0.7771 & Interest & 0.9258 \\
ITSOPH5 & 0.8796 & INTRST1 & 0.9144 \\
ITSOPH6 & 0.8428 & INTRST2 & 0.9005 \\
& 0.8195 & INTRST3 & 0.9098 \\
Choice Goals & 0.8544 & INTRST4 & 0.8168 \\
CGOAL1 & & INTRST5 & \\
CGOAL2 & & & \\
CGOAL3 & 0.9807 & & \\
CGOAL4 & 0.9683 & & \\
\hline \hline
\end{tabular}

\section{Structural Model Analysis}

Statistical significance of the paths was determined using two-tailed t-tests calculated using the bootstrap resampling method. All constructs were modeled as reflective and included in the model using multiple indicators (Karahanna, Agarwal, \& Angst, 2006). The results of the structural model analysis are represented in Figure 3.

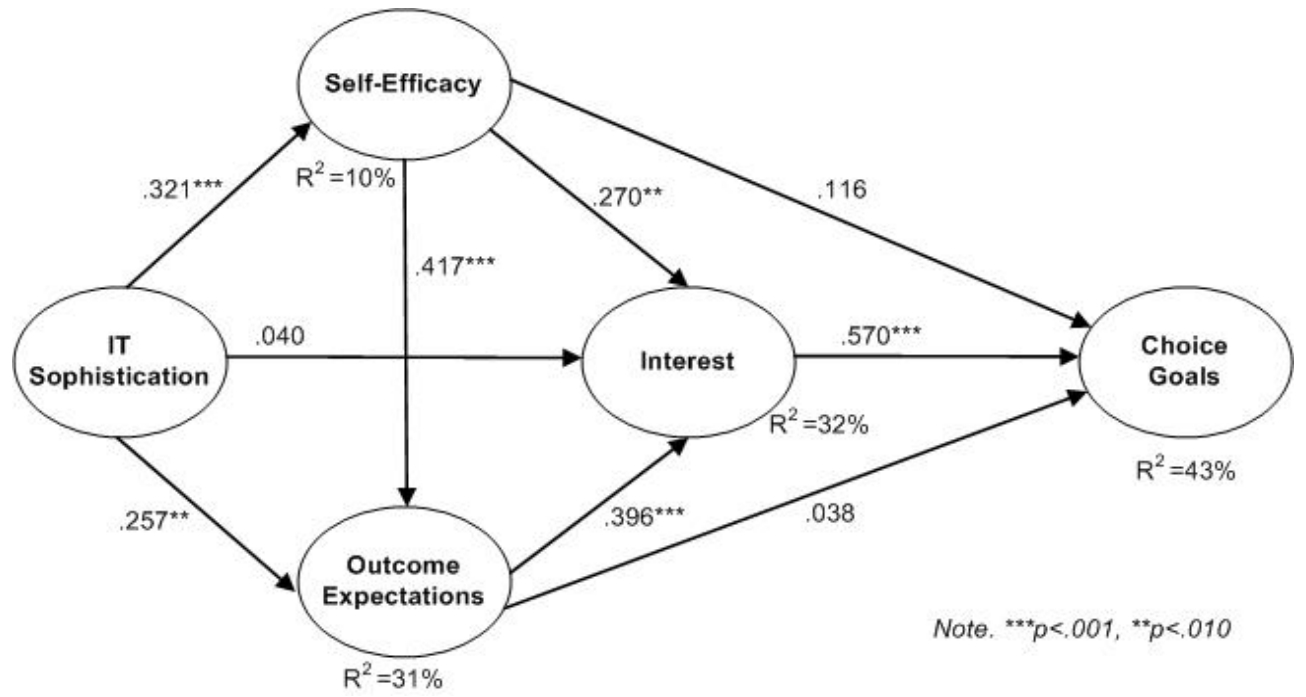

Figure 3: Structural Model Results 
Table 3 provides a summary of hypotheses testing. The results indicate that the model explains a sizeable proportion of the variance in choice goals ( 43 percent), interest ( 32 percent), outcome expectations (31 percent), and self-efficacy (10 percent).

Despite our expectations, IT sophistication was not a significant predictor of interest $(0.040, n s)$. Therefore no support was offered for $\mathrm{H}_{1}$. As expected, IT sophistication was a significant predictor of self-efficacy $(0.321, p<0.001)$ and outcome expectations $(0.257, p<0.01)$, supporting hypotheses $\mathrm{H}_{2}$ and $\mathrm{H}_{3}$.

Self-efficacy was found to be a significant predictor of outcome expectations $(0.417, p<0.001)$ and interest $(0.270, p<0.01)$. Therefore, hypotheses $\mathrm{H}_{4}$ and $\mathrm{H}_{5}$ were supported. On the other hand, self-efficacy did not serve as a significant predictor of choice goals $(0.116, n s)$. As a result, no support was offered for hypothesis $\mathrm{H}_{6}$.

Outcome expectations was a significant predictor of interest $(0.396, p<0.001)$, supporting hypothesis $\mathrm{H}_{7}$. However, in opposition to our expectations, outcome expectations did not have a significant influence on choice goals $(0.038, n s)$. Therefore, hypothesis $\mathrm{H}_{8}$ was not supported. Finally, interest was found to be a significant predictor of choice goals $(0.570, p<0.001)$, supporting hypothesis $\mathrm{H}_{9}$.

Table 3. Summary of Hypotheses Testing

\begin{tabular}{|c|c|c|c|c|c|}
\hline \multicolumn{2}{|c|}{ Hypothesis } & \multirow{2}{*}{$\begin{array}{l}\text { Coef. } \\
-0.040\end{array}$} & \multirow{2}{*}{$\begin{array}{r}\boldsymbol{t} \text {-stat } \\
0.466\end{array}$} & & \multirow{2}{*}{$\begin{array}{l}\text { Conclusion } \\
\text { Not supported }\end{array}$} \\
\hline$H_{1}:$ & $\begin{array}{l}\text { IT sophistication will have a significant } \\
\text { positive influence on interest. }\end{array}$ & & & & \\
\hline$H_{2}:$ & $\begin{array}{l}\text { IT sophistication will have a significant } \\
\text { positive influence on self-efficacy. }\end{array}$ & 0.321 & 4.800 & $* * *$ & Supported \\
\hline$H_{3}:$ & $\begin{array}{l}\text { IT sophistication will have a significant } \\
\text { positive influence on outcome expecta- } \\
\text { tions. }\end{array}$ & 0.257 & 3.051 & $* *$ & Supported \\
\hline$H_{4}:$ & $\begin{array}{l}\text { Self-efficacy will have a significant posi- } \\
\text { tive influence on outcome expectations. }\end{array}$ & 0.417 & 5.313 & $* * *$ & Supported \\
\hline$H_{5}:$ & $\begin{array}{l}\text { Self-efficacy will have a significant posi- } \\
\text { tive influence on interest. }\end{array}$ & 0.270 & 2.958 & $* *$ & Supported \\
\hline$H_{6}:$ & $\begin{array}{l}\text { Self-efficacy will have a significant posi- } \\
\text { tive influence on choice goals. }\end{array}$ & 0.116 & 1.717 & & Not Supported \\
\hline$H_{7}:$ & $\begin{array}{l}\text { Outcome expectations will have a sig- } \\
\text { nificant positive influence on interest. }\end{array}$ & 0.396 & 4.273 & $* * *$ & Supported \\
\hline$H_{8}:$ & $\begin{array}{l}\text { Outcome expectations will have a sig- } \\
\text { nificant positive influence on choice } \\
\text { goals. }\end{array}$ & 0.038 & 0.547 & & Not supported \\
\hline$H_{9}:$ & $\begin{array}{l}\text { Interest will have a significant positive } \\
\text { influence on choice goals. }\end{array}$ & 0.570 & 8.842 & $* * *$ & Supported \\
\hline
\end{tabular}

\section{Discussion}

Over the past few years, there has been a decline in the number of students pursuing IS degrees. In order to overcome this situation, the IS community has started to look for mechanisms to refuel student interest in the discipline. To address this important issue, we investigated how such a mechanism - IT sophistication - influences students' aspirations to pursue an IS degree. As such, our findings have important implication for IS programs, as the information gained herein can be 
utilized to design and implement a specific intervention strategy to attract larger pools of students to the IS discipline.

Specifically, our findings indicate that teaching sophisticated IT in introductory IS courses plays an important role in student uptake. Teaching sophisticated IT promotes students' self-efficacy and outcome expectations. Utilizing state-of-the art technologies that reflect current industry practices not only enhances students' confidence in their ability to successfully perform as an IS major, but also elevates students' expectations that valued rewards will be received by majoring in IS. Unexpectedly, our results failed to provide support for the direct effects of IT sophistication on student interest. Rather, the effects of IT sophistication on interests are channeled indirectly through self-efficacy and outcome expectations. In essence, strong self -efficacy and outcome expectations were found to foster student interest in the IS discipline. Therefore, it is reasonable to assume that students are more likely to develop an interest in the IS discipline when they feel efficacious and expect to receive valued rewards. However, our results did not provide support for the direct effects of self-efficacy and outcome expectations on choice goals. In contrast, choice goals develop through strong interests, which evolve, in part, from a robust sense of efficacy and outcome expectations. It was also found that self-efficacy leads to more robust outcome expectations. Not surprisingly, students who deem themselves as capable of majoring in IS perceive that value rewards are more likely to be obtained. Finally, our findings also provided strong support for the positive relationship between interests and choice goals, confirming that interest serves as the primary mechanism though which goals to choose IS major emerges.

As a result of this study, we have gained a theoretical understanding of the role IT sophistication can play in the student recruitment process. The model not only supports the notion that IT sophistication can be used to attract larger pools to the IS discipline, but also explains how and why IT sophistication influences the student aspirations. As a result of the study, we can confidently state that deploying sophisticated technologies in introductory IS courses promotes students' goals to pursue the IS major. The findings lead to the conclusion that deploying sophisticated IT in introductory IS classes can be used as a powerful lever to attract additional students the IS discipline. Therefore, we encourage those who teach introductory IS courses to focus on state-ofthe-art technologies that reflect current industry practices. In doing so, IS programs should witness a boost in student confidence and expectations of value rewards will be obtained by pursuing an IS degree. Ultimately, these effects stimulate student interest, which helps students develop aspirations to choose IS as a major. Utilizing these technologies also has the potential to increase student success in the classroom, provide a richer and more engaging learning environment for students, and help students become more attractive to recruiters.

Despite the knowledge gained herein, some cautions are warranted. The constructs in the research model represent a relatively limited subset of the factors that could plausibly affect student choices. In order to develop a more comprehensive set of intervention strategies targeted at student recruitment, a wider range of factors needs to be considered and validated. The research model can be readily adapted to study these factors and potential barriers that might be impairing student enrollments. In addition, we utilized a survey to examine the relationships among the variables in the model. Although the measures exhibited sufficient levels of reliability and validity, it is plausible that self-reported data could have resulted in common method variance, artificially inflating the relationships among the variables. Finally, this study did not control for other factors, such as pedagogical differences between the two data collection sites. We, therefore, recommend that the model be confirmed using classes that are similar except for the type of technology utilized. In total, future studies should utilize additional methods using complementary samples to identify the boundary conditions of our findings. 


\section{Conclusion}

This study investigated the role that the level of technological sophistication in introductory IS courses plays in attracting students to the IS discipline. Grounded in Social Cognitive Theory, the study found that the degree to which students perceive the IT to be sophisticated affects student aspiration to major in IS. Specifically, IT sophistication enhances students' confidence in their ability to successfully perform as an IS major (i.e., self-efficacy) and elevates students' expectations that valued rewards will be received by majoring in IS (i.e., outcome expectations). In turn, strong self-efficacy and outcome expectations foster student interest in the IS discipline. Interest serves as the primary mechanism through which goals to choose the IS major emerge. As a result of this study, we can confidently recommend that IS programs deploy sophisticated technologies in their introductory IS course. By implementing this recommendation, programs should witness an uptick in student enrollments. Nonetheless, the research model does not capture all the factors that could plausibly affect student enrollments. Additional research is clearly needed to identify other intervention strategies that could help reverse the sharp decline in IS majors.

\section{References}

Agarwal, R., Sambamurthy, V., \& Stair, R.M. (2000). Research report: The evolving relationship between general and specific computer self-efficacy - An empirical assessment. Information Systems Research, $11(4), 418-430$.

Bandura, A. (1986). Social foundation of thought and action: A social cognitive theory. Englewood Cliffs, NJ: Prentice Hall.

Bandura, A. (1997). Self-efficacy: The exercise of control. New York: W.H. Freeman and Company.

Bandura, A. (1999). Social cognitive theory of personality. In L. Pervin \& O. John (Eds.), Handbook of Personality (2nd ed.) (pp. 154-196). New York: Gailford Press.

Bandura, A. (2000). Exercise of human agency through collective efficacy. Current Directions in Psychological Science, 9, 75-78.

Bandura, A., \& Schunk, D. H. (1981). Cultivating competence, self-efficacy, and intrinsic interest through proximal self-motivation. Journal of Personality and Social Psychology, 56, 805-814.

Berlyne, D. F. (1978). Curiosity and learning. Motivation and Emotion 2(1), 97-175.

Barclay, D., Higgins, C., \& Thompson, R. (1995). The partial least squares approach to causal modeling: Personal computer adoption and use as an illustration. Technology Studies, 2, 285-324.

Chwelos, P., Benbasat, I., \& Dexter, A. S. (2001). Research report: Empirical test of an EDI adoption model. Information Systems Research, 12(3), 304-321.

Compeau, D. R., \& Higgins, C. A. (1995a). Application of social cognitive theory to training for computer skills. Information Systems Research, 6, 118-143.

Compeau, D. R., \& Higgins, C. A. (1995b). Computer self-efficacy: Development of a measure and initial test. MIS Quarterly, 19, 189-211.

Compeau, D. R., Higgins, C. A., \& Huff, S. (1999). Social cognitive theory and individual reactions to computing technologies. MIS Quarterly, 23, 145-158.

Chin, W. W. (2003). PLS Graph, Version 03.00. Department of Decision and Information Systems, University of Houston.

Fornell, C., \& Larker, D. F. (1981). Evaluating structural equation models with unobserved variables and measurement error. Journal of Marketing Research, 18, 39-50.

Gefen, D., Straub, D.W., \& Boudreau, M.C. (2000). Structural equation modeling and regression: Guidelines for research practice. Communications of the AIS, 4 (7), 1-77. 
George, J. F., Valacich, J. S., \& Valor, J. (2005). Does information systems still matter? Lessons for a maturing discipline. Communications of the AIS, 16, 219-232.

Hecker, D. E. (2004). Employment projections through 2012. Monthly Labor Review. U.S. Bureau of Labor Statistics, Washington, DC.

Holland, J. L. (1985). Making vocational choices: A theory of vocational personalities and work environments (2nd ed.). Englewood Cliffs, NJ: Prentice Hall.

Johnson, R. D., \& Marakas, G. M. (2000) Research report: The role of behavioral modeling in computer skill acquisition: Toward refinement of the model. Information Systems Research, 11(4), 402-417.

Joreskog, K. G., \& Sorbom, D. (1993).Lisrel 8: Structural equation modeling with SIMPLIS command language. Hillside, NJ: Lawrence Erlbaum Associates.

Kamoun, F., \& Selim, S. (2007). A framework towards assessing the merits of inviting IT professionals to the classroom. Journal of Information Technology Education, 6, 81-103. Retrieved from http://jite.org/documents/Vol6/JITEv6p081-103Kamoun223.pdf

Karahanna, E., Agarwal, R., \& Angst, C. M. (2006). Reconceptualizing compatibility beliefs in technology acceptance research. MIS Quarterly, 3(4), 781-804.

Kegely, K. A. (2006). SimNet XPert: An effective and innovative component of an e-learning course for Microsoft Office applications. McGraw-Hill Education Website: McGraw-Hill, New York.

Lent, R. W., Brown, S. D., \& Hackett, G. (1994). Toward a unifying social cognitive theory of career and academic interest, choice, and performance. Journal of Vocational Behavior, 45, 79-122.

Lent, R. W., Brown, S. D., Nota, L., \& Soresi, S. (2003). Testing social cognitive interest and choice hypotheses across Holland types in Italian high school students. Journal of Vocational Behavior, 62, 101118.

Lent, R. W., Brown, S. D., Talleyrand, R., McPartland, E. B., Davis, T., Chopra, S. B., Alexander, M. S., et al. (2002). Career choice barriers, supports, and coping strategies: college students' experiences. Journal of Vocational Behavior, 60, 61-72.

Lomerson, W. L., \& Pollicia, L. (2006). CIS enrollment decline: Examining pre-college factors. Proceedings of the 2006 Southern Association for Information Systems Conference, 93-103.

Looney, C. A., Valacich, J. S., Todd, P. A., \& Morris, M. G. (2006). Paradoxes of online investing: Testing the influence of technology on user expectancies. Decision Sciences, 37(2), 205-246.

Marakas, G. M., Yi, M. Y. \& Johnson, R. D. (1998). The multilevel and multifaceted character of computer self-efficacy: Toward a clarification of the construct and an integrated framework for research. Information Systems Research, 9, 126-162.

Nam, C. S., \& Smith-Jackson, T. L. (2007). Web-based learning environment: A theory-based design process for development and evaluation. Journal of Information Technology Education, 6, 23-43. Retrieved from http://jite.org/documents/Vol6/JITEv6p023-043Nam145.pdf

Staples, D. S., Hulland, J. S., \& Higgins, C.A. (1999). A self-efficacy theory explanation for the management of remote workers in virtual organizations. Organization Science, 10(6), 758-776.

Taylor, S. \& Todd, P. A. (1995). Understanding information technology usage: A test of competing models. Information Systems Research, 6(2), 144-176.

Wold, H. (1985) Systems analysis by partial least squares. In P. Nijkamp, L. Leitner, \& N. Wrigley (Eds.), Measuring the unmeasurable (pp. 221-251). Dordrecht: Marinus Nijhoff. 


\section{Biographies}

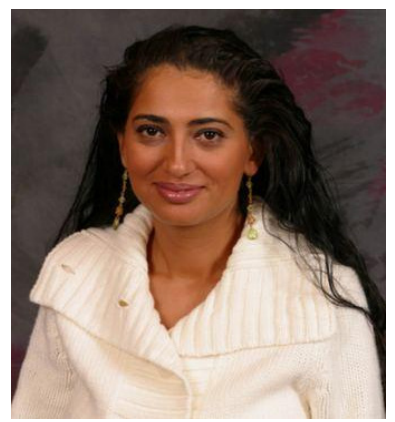

Asli Yagmur Akbulut is an Assistant Professor of Management Information Systems at the Seidman College of Business at Grand Valley State University. She is the recipient of the 2007 university-wide Pew Teaching Excellence award. Dr. Akbulut earned her Ph.D. and M.S. degrees in Information Systems and Decision Sciences from Louisiana State University. She also holds an M.B.A. degree. Her research interests include the application of Social Cognitive Theory in IS, humancomputer interaction, IS education, information sharing, and enterprise systems. Her work has appeared or is forthcoming in Communications of the ACM, Communications of the AIS, Journal of Computer Information Systems, International Journal of Business Information Systems, International Journal of Production Economics, International Journal of Automotive Technology and Management, International Journal of Services and Operations Management, Journal of International Technology and Information Management, Journal of Information Technology Cases and Applications, and various international conferences.

Clayton Arlen Looney is an Assistant Professor and the Ron and Judy Paige Faculty Fellow in

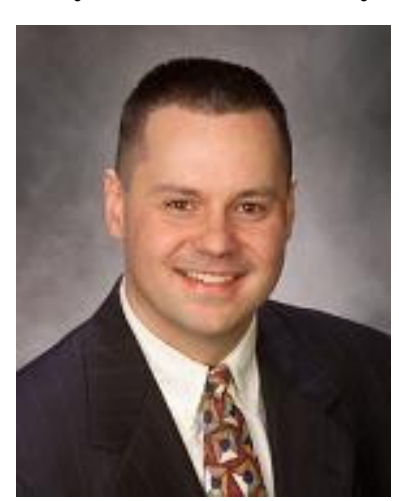
the School of Business Administration at the University of Montana. He earned his Ph.D. in Information Systems from Washington State University. His areas of expertise involve electronic commerce, human-computer interaction, and decision support systems. Being the recipient of numerous teaching awards, much of his recent work has focused on understanding the effects of various teaching practices on student learning and decision making. His work has appeared in Communications of the ACM, Communications of the AIS, Decision Sciences, Group Dynamics: Theory, Research, and Practice, International Journal of Business Information Systems, and Journal of Computer Information Systems, as well as various international conferences. 